\section{Knowledge, attitude and practices on anti-tobacco measures imposed under the Cigarette and Other Tobacco Products Act among adult males in rural areas of Tamil Nadu, India}

Kalaivani Annadurai, Raja Danasekaran, Geetha Mani

Department of Community Medicine, Shri Sathya Sai Medical College and Research Institute, Ammapettai, India

\section{Abstract}

Assessment of knowledge and attitude of adult men towards anti-tobacco measures will help us further in strengthening of regulatory activities and thereby reducing the prevalence of tobacco use. The objective of the present study was i) to assess the knowledge of men towards anti-tobacco measures imposed under Cigarette and Other Tobacco Products Act 2003 and its association with their socio-demographic factors; and ii) to study the attitudes and practice of men towards anti-tobacco measures imposed under COTPA 2003. A cross-sectional study was done among 714 males aged 18 years and above in Vadagarai village of Thiruvallur district of Tamil Nadu and interviewed with pretested questionnaire. The study was done during March to September 2009. Majority of them were aware and favoring the act, i.e. $96.2 \%$ of the study population were aware of the COTPA 2003 and $95.24 \%$ were favoring the act. Most of them felt that anti-tobacco measures did not have any impact among tobacco users. Preventive steps like behavioral change communication, fiscal measures and further more strong enforcement of the act will be needed to decrease the prevalence further.

\section{Introduction}

Tobacco use is a serious public health problem. Tobacco is a risk factor for six of the eight leading causes of deaths in the world. ${ }^{1}$ Every eight seconds someone, somewhere in the world, dies as a result of tobacco use. Around five million people die globally every year due to the effect of tobacco and this is likely to exceed eight million by 2030. ${ }^{2}$ The International Classification of Diseases (ICD10) has recognized that tobacco dependence is a disease. ${ }^{3}$ Tobacco use causes a wide range of major diseases which impact nearly every organ of the body. These include several types of cancers, coronary heart disease, cerebrovascular disease and lung diseases. ${ }^{4}$ Research has generated scientific evidence that secondhand smoke causes the same problems as direct smoking, including cardiovascular disease, lung cancer, and lung ailments such bronchitis and asthma attacks. ${ }^{5-8}$ World Health Organization (WHO) recommends five policies for controlling tobacco use: smoke-free environments; support programmes for tobacco users who wish to stop; health warnings on tobacco packs; bans on the advertising, promotion and sponsorship of tobacco; and higher taxation of tobacco. ${ }^{9}$ In India, tobacco consumption continues to grow at $2-3 \%$ per annum. ${ }^{10}$ India's anti-tobacco legislation, first passed at the national level in 1975, was largely limited to health warnings and proved to be inefficient. The adoption of a WHO Framework Convention on Tobacco Control (WHO FCTC) by the World Health Assembly on 24th May 1999 was an important landmark to achieve comprehensive tobacco control worldwide. ${ }^{11}$ India was the $7^{\text {th }}$ country that ratified the WHO FCTC on $5^{\text {th }}$ February 2004. In 2003, The Central Government passed the Cigarettes and Other Tobacco Products Act (COTPA) applicable to all tobacco products. ${ }^{12}$ Maximum number of violations were recorded in Tamil Nadu and ranks first among the states. A total of 9,648 people have been fined and a whopping Rs 11,42,950 collected as fine from the southern state for violating the ban on smoking in public places in effect since October $2^{\text {nd }} 2007 . .^{13}$ Due to the scarcity of studies regarding the awareness of COTPA, this study was done to assess the knowledge, attitude and practices of adult males towards anti-tobacco measures imposed under the act.

\section{Materials and Methods}

A cross sectional study was done among adult males aged 18 years and above in Vadagarai village in Thiruvallur district of Tamil Nadu.

The sample size was calculated on the basis of $35 \%$ prevalence rate of smoking in rural area according to NFHS-3 survey with allowable error $10 \%$, sample size came to $714 .{ }^{14}$ Vadagarai HSC was chosen randomly from Naravarikuppam block Primary Health Centre. In order to get 714 men aged 18 years and above, it was decided to survey 445 households in Vadagarai subcenter, with a total of 1581 households with population of 2539 men above 18 years. The households were sampled by systematic random sampling. The sampling interval was 4 and the first household was selected randomly choosing a number within the sample interval. The next household was
Correspondence: Dr. Kalaivani Annadurai, Department of Community Medicine, Shri Sathya Sai Medical College and Research Institute, Tiruporur-Guduvancherry Main Road, Ammapettai 603108 , India.

Tel. +44.919500029829 - Fax: +44.27440138 .

E-mail: drkalaimdspm@gmail.com

Key words: tobacco, COTPA, socio-demographic factors, regulatory activities.

Contributions: KA, RD, data collecting and analyzing; GM, manuscript writing.

Conflict of interests: the authors declare no potential conflict of interests.

Acknowledgements: we are thankful to those who have participated in the study.

Received for publication: 15 August 2013.

Revision received: 19 September 2013.

Accepted for publication: 25 September 2013.

This work is licensed under a Creative Commons Attribution 3.0 License (by-nc 3.0).

(C) Copyright K. Annadurai et al., 2014

Licensee PAGEPress, Italy

Healthcare in Low-resource Settings 2014; 2:1883 doi:10.4081/hls.2014.1883

identified by adding the sampling interval with the first randomly chosen number and only one adult male was interviewed in each house. If there were more than one adult male in the same house, the participant was randomly chosen using lot system and then interviewed.

A semi-structured questionnaire was used. It was translated into local language, pretested and standardized. It consisted of three parts of which Part I deals with questions related to socio-demographic profile, Part II deals with questions regarding their knowledge and attitude towards anti-tobacco measures imposed under COTPA 2003 and Part III deals with questions regarding their practice towards anti-tobacco measures. The interview was conducted in the house of the participants by the investigators themselves.

Data entry was made in Excel software in codes and analysis was done by SPSS software. Levels of awareness, attitude and practices regarding COTPA were expressed in percentage and their association with socio demographic factors was tested for significance using chi-square test.

\section{Results}

Mean age of the sample population was $35.34 \pm 13.98$ years with range of $18-85$ years. 
Half of them were between 18-30 years. Most of them were Hindus (82.5\%). Literacy rate of the sample population seems to be high (88.09\%). Half of the participants were from upper lower socio economic group (49.01\%) and about two third (76.05\%) were unskilled, semi-skilled and skilled laborers (Table 1).

\section{Awareness about COTPA}

Analysis of the study population shows that $96.2 \%$ were aware of the COTPA 2003, the awareness regarding anti-tobacco measures showed that $96.2 \%$ knew that smoking was prohibited in public place and $88.0 \%$ knew that there was an age limit below which sale of tobacco products was banned. Source of information were newspaper (36.39\%), television (21.83\%), radio (10.77\%), friends (4.37\%) and a combination of all (26.64\%) (Tables 2 and 3 ). There was a statistically significant association between the level of education and awareness about the act and its regulations $(\mathrm{P}<0.0001)$ (Table 4).

\section{Smokers and COTPA}

Out of 714 study population, 262 (36.7\%) were smokers. Among smokers 92.4\% were aware of the act and $88.5 \%$ of smokers were favoring the ban on smoking in public places. About violation of act among smokers
( $n=262$ ), 8.0\% were fined for smoking in public place. Regarding the effect of COTPA among smokers $(n=262), 65.8 \%$ were of the opinion that the act did not change their smoking pattern, 33.8\% told that anti-tobacco measures reduced their smoking habit and $0.4 \%$ quit totally due to this regulation.

\section{Discussion}

Studies done in Andhra Pradesh ${ }^{15}$ and Assam $^{16}$ in India have reported awareness of COTPA as 47.5 and $45.7 \%$ respectively. Our

Table. 1 Socio-demographic details of the participants.

\begin{tabular}{ccccccccccccccc} 
Age & $\mathbf{N}$ & $\%$ & Occupation & $\mathbf{N}$ & $\%$ & Religion & $\mathbf{N}$ & $\%$ & Socio-economic status & N & $\%$ & Education & N \\
$18-30$ & 357 & 50 & Unemployed/student & 39 & 5.46 & Hindus & 589 & 82.5 & Upper (Class-I) & 13 & 1.82 & Illiterate & 85 & 11.91 \\
$31-40$ & 112 & 16.68 & Unskilled/semiskilled/skilled & 543 & 76.05 & Christians & 87 & 12.2 & Upper middle (Class-II) & 87 & 12.18 & Literate & 629 & 88.0 \\
\hline $41-50$ & 123 & 17.23 & Clerk, shop-owner, farm-owner & 97 & 13.59 & Muslims & 38 & 5.3 & Lower middle (Class-III) & 160 & 22.40 & & \\
$51-60$ & 93 & 13.02 & Semiprofessional/professional & 13 & 1.82 & & & & Upper lower (Class-IV) & 350 & 49.01 & \\
\hline 21 & 29 & 4.06 & Retired/old age dependent & 22 & 3.08 & & & & Lower (Class-V) & 104 & 14.56 & \\
\hline
\end{tabular}

Table 2. Age group in years, their awareness of COTPA and prohibition of smoking in public place.

\begin{tabular}{ccccc} 
Agge & $\begin{array}{c}\text { Total } \\
(\%)\end{array}$ & Aware of COTPA & $\begin{array}{c}\text { Aware about prohibition } \\
\text { of smoking in public places }\end{array}$ & $\begin{array}{c}\text { Aware about age } \\
\text { limit for sale of tobacco }\end{array}$ \\
\hline $18-30$ & $357(50 \%)$ & $351(98.3 \%)$ & $351(98.3 \%)$ & $329(92.16 \%)$ \\
$31-40$ & $112(16.68 \%)$ & $107(95.54 \%)$ & $107(95.54 \%)$ & $95(84.82 \%)$ \\
\hline $41-50$ & $123(17.23 \%)$ & $118(95.93 \%)$ & $118(95.93 \%)$ & $110(89.43 \%)$ \\
$51-60$ & $93(13.02 \%)$ & $91(97.85 \%)$ & $91(97.85 \%)$ & $80(86.02 \%)$ \\
\hline$>61$ & $29(4.06 \%)$ & $20(68.96 \%)$ & $20(68.96 \%)$ & $16(55.17 \%)$ \\
Total & $714(100 \%)$ & $687(96.2 \%)$ & $687(96.2 \%)$ & $630(88.2 \%)$ \\
\hline
\end{tabular}

COTPA, Cigarette and Other Tobacco Products Act.

Table 3. Education status and awareness of COTPA.

\begin{tabular}{lccccccc}
$\begin{array}{l}\text { Educational } \\
\text { status }\end{array}$ & $\begin{array}{c}\text { Total } \\
(\%)\end{array}$ & Awareness of COTPA & $\begin{array}{c}\text { Awareness about prohibition } \\
\text { of smoking in public places } \\
\text { P }\end{array}$ & $\begin{array}{c}\text { Awareness about age } \\
\text { limit for sale of tobacco } \\
\text { N (\%) }\end{array}$ \\
Illiterate & $85(11.9 \%)$ & $70(82.4 \%)$ & $<0.0001$ & $70(82.4 \%)$ & $<0.0001$ & $60(70.6 \%)$ \\
Primary school & $292(40.9 \%)$ & $285(97.6 \%)$ & $<0.0001$ & $285(97.6 \%)$ & $<0.0001$ & $260(89.0 \%)$ & $<0.0001$ \\
\hline Middle school & $237(33.19 \%)$ & $232(97.9 \%)$ & $<0.0001$ & $232(97.9 \%)$ & $<0.0001$ & $215(90.7 \%)$ & $<0.0001$ \\
High school & $49(6.86 \%)$ & $49(100.0 \%)$ & $<0.0001$ & $49(100.0 \%)$ & $<0.0001$ & $44(89.8 \%)$ & $<0.0001$ \\
College/diploma & $51(7.14 \%)$ & $51(100.0 \%)$ & $<0.0001$ & $51(100.0 \%)$ & $<0.0001$ & $49(96.1 \%)$ & $<0.0001$ \\
\hline Total & $714(100.00 \%)$ & $687(96.2 \%)$ & $<0.0001$ & $687(96.2 \%)$ & $<0.0001$ & $628(88.0 \%)$ & $<0.0001$ \\
\hline
\end{tabular}

COTPA, Cigarette and Other Tobacco Products Act.

Table 4. Attitude towards COTPA and anti-tobacco measures.

\begin{tabular}{lccc} 
Variable & & \multicolumn{1}{c}{ Attitude (\%) } \\
Negative & Positive & Do not know \\
About COTPA and its regulation & $680(95.24)$ & $34(4.76)$ & - \\
Implementation of ban on smoking in public places by government authorities & $189(26.5)$ & $455(63.7)$ & $70(9.8)$ \\
\hline Pictorial health warning & $189(26.5)$ & $427(59.8)$ & $98(13.7)$ \\
\hline
\end{tabular}

COTPA, Cigarette and Other Tobacco Products Act. 
study found the awareness level to be $96.2 \%$ which was far better than the above studies. Similar finding was observed in Rakesh et al. where it was found to be $88 \%$ among members of Panchayat raj institution, Haryana. ${ }^{17}$

Of the age group between 18-25 years, $97.8 \%$ were aware of the act and of prohibition of smoking in public places. $69.0 \%$ of the age group above 61 years were aware of the act and prohibition of smoking in public places. So, young people were more aware of the act than elders. Of the age group between 18-25 years, $92.0 \%$ was aware that there was age limit below which sale of tobacco products was banned. Of the age group above 61 years, $55.2 \%$ was aware of the age limit. So, young people were more aware of the age limit below which sale of tobacco products was banned. This finding was contradictory to the findings from Rao et al. ${ }^{15}$ and Sharma et al. ${ }^{16}$ where they found that the awareness of COTPA increased significantly with increasing age. Of literates, $98.1 \%$ were aware of the act and were aware of prohibition of smoking in public places. Of illiterates, $82.8 \%$ was aware of the act and were aware of prohibition of smoking in public places. Literates were more aware about the act than illiterates. Rao et al. ${ }^{15}$ and Sharma et al. ${ }^{16}$ have reported similar findings. Of literates, $90.3 \%$ and $70.6 \%$ of illiterates were aware of age limit below which sale of tobacco products was banned.

Analysis shows that majority of them, i.e. $95.24 \%$ were favoring the act; this was similar to the findings from Rao et al. ${ }^{15}$ Sharma et al. ${ }^{16}$ and American University of Armenia ${ }^{18}$ Majority of the study population, i.e. $63.7 \%$ felt that measures against smoking in public places were not followed correctly. Moreover, more than half, $59.8 \%$ felt that pictorial health warning did not have any impact on smoking habit.

Among smokers $92.4 \%$ were aware of the act and most of them, i.e. $88.5 \%$ of smokers were favoring the ban on smoking in public places. In addition $8.0 \%$ of smokers were fined for violating the ban on smoking in public places. Regarding quitting, $33.8 \%$ of smokers reported that their smoking habit got reduced because of the anti-tobacco measures under the act. In countries with pictorial health warnings, such as Canada and Australia, these numbers were higher: more than $40 \%$ of Canadian smokers reported that the pictorial warnings have motivated them to quit smoking; ${ }^{19}$ in Australia, picture warnings have supported $62 \%$ of former smokers in their efforts to quit. ${ }^{19}$ In our study, $0.4 \%$ reported that they had totally quit smoking because of fine due to violation but majority of them, i.e. $56.9 \%$ reported that act did not have any impact on their smoking habit.

\section{Conclusions}

Majority of the participants were aware of the act and favoring the act. But most of them felt regulations under the act were not followed properly. Most of the smokers felt that anti-tobacco measures imposed under the act did not have any impact on their smoking status. The policy makers should consider newer options such as starting a help line for quitting tobacco to regulate the use of tobacco with consideration that most of the smokers were reluctant in quitting tobacco even after the implementation of various anti-tobacco measures under COTPA. Apart from these steps, counselling sessions have to be arranged for those tobacco users who are reluctant to quit. To conclude, the steps taken by the government bodies in the future should be strictly followed and it should be continuously monitored.

\section{References}

1. WHO. Tobacco free initiative. Tobacco facts. Geneva, Switzerland: World Health Organization; 2013. Available from: http://www.who.int/tobacco/mpower/tobacco_facts/en/

2. Leung CM, Leung AK, Hon KL, Kong AY. Fighting tobacco smoking: a difficult but not impossible battle. Int $\mathbf{J}$ Environ Heal $\mathbf{R}$ 2009;6:69-83.

3. WHO. International statistical classification of diseases and related health problems. Geneva, Switzerland: World Health Organization; 2010. Available from: http//www.who.int/classifications/icd/ICD10 Volume2_en_2010.pdf

4. CDC. Smoking and tobacco use. Atlanta, GA, USA: Centers for Disease Control and Prevention; 2013. Available from: http:/www. cdc.gov/tobacco/data_statistics/fact_sheets/h ealth_effects/effects_cig_smoking/

5. US Department of Health and Human Services. The health consequences of involuntary exposure to tobacco smoke: a report of the surgeon general. Washington, DC, USA: Department of Health and Human Services; 2006. Available from: www.surgeongeneral. gov/library/reports/secondhand-smoke-consumer.pdf

6. California Environmental Protection Agency. Health effects assessment for environmental tobacco smoke. Sacramento, CA, USA: California Environmental Protection Agency; 2005. Available from: www.oehha.ca. gov/air/environmental_tobacco/pdf/app3part b2005.pdf

7. IARC. Tobacco smoke and involuntary smoking. Lyon, France: International Agency for Research on Cancer; 2004. Available from: http:/monographs. iarc.fr/ENG/ Monographs/ vol83/mono83-1.pdf

8. American Cancer Society. Cancer facts and figures 2012. Atlanta, GA, USA: American Cancer Society; 2012. Available from: http//www.cancer.org/cancer/cancercauses/t obaccocancer/secondhand-smoke

9. WHO. An international treaty for tobacco control. Geneva, Switzerland: World Health Organization; 2003. Available from: http//www.who.int/features/2003/08/en/

10. Jandoo T, Mehrotra R. Tobacco control in India: present scenario and challenges ahead. Asian Pac J Cancer P 2008;9:805-10.

11. WHO. Frame work convention on tobacco control. Guidelines for implementation. Geneva, Switzerland: World health organization; 2005. Available from: http://apps.who.int/iris/bitstream/10665/ 80510/1/9789241505185_eng.pdf?ua=1

12. Government of India. The cigarettes and other tobacco products (prohibition of advertisement and regulation of trade and commerce, production, supply and distribution) Act, 2003, and rules framed there under. Available from: http:/indiacode.nic.in/fullactl.asp?tfnm=200334

13. Tamil Nadu records highest number of smoking violation (2009, May 26). Hindustantimes. Available from: http//www. hindustantimes.com/India-news/NewDelhi/ Tamil-Nadu-records-highest-number-ofsmoking-violation/Article1-414543.aspx

14. IIPS. National Family Health Survey (NFHS3) 2005-06. Mumbai, India: International Institute for Population Sciences; 2007.

15. Rao AR, Dudala SR, Bolla CR, Kumar BPR. Knowledge attitude and practices regarding the cigarettes and other tobacco products act (COTPA) in Khammam, Andhra Pradesh. Int J Res Health Sci 2013;1:96-102.

16. Sharma I, Sarma PS, Thankappan KR. Awareness, attitude and perceived barriers regarding implementation of the Cigarettes and Other Tobacco Products Act in Assam, India. Indian J Cancer 2010;47:63-8.

17. Rakesh K, Misra P. Knowledge, attitude and practice regarding anti-tobacco measures among members of panchayat raj institution in a rural area of Haryana. Indian J Publ Health 2011;55:339-40.

18. American University of Armenia. KAP Tobacco control policies in adult population in Armenia a follow- up survey. Yerevan, Armenia: American University of Armenia, Center for Health Services Research and Development; 2007. Available from: http://auachsr.com/UserFiles/File/RITC\%20Fo llow\%20Up\%20Report_2007.pdf

19. Hammond D, Fong GT, Borland R. Text and graphic warnings on cigarette packages: findings from the international tobacco control four country study. Am J Prev Med 2007;32:202-9. 